\title{
Hypofractionation: less is more?
}

\author{
Neethu Billy Graham Mariam ${ }^{1}$, Yee Pei Song ${ }^{1,2}$, Nuradh Joseph ${ }^{3}$, Peter Hoskin ${ }^{2,4}$, \\ Kimberley Reeves ${ }^{2}$, Nuria Porta ${ }^{5}$, Nicholas James ${ }^{6}$ and Ananya Choudhury ${ }^{1,2}$ \\ ${ }^{1}$ Department of Clinical Oncology, The Christie NHS Foundation Trust, Manchester, UK \\ ${ }^{2}$ Division of Cancer Sciences, School of Medical Sciences, Faculty of Biology, Medicine and Health, University of Manchester, \\ Manchester, UK \\ ${ }^{3}$ Ministry of Health, Colombo, Sri Lanka \\ ${ }^{4}$ Mount Vernon Cancer Centre, Northwood, UK \\ ${ }^{5}$ Clinical Trials and Statistics Unit, The Institute of Cancer Research, London, UK \\ ${ }^{6}$ Prostate and Bladder Cancer Research Team, The Institute of Cancer Research, London, UK \\ Correspondence to: Ananya Choudhury, email: ananya.choudhury@nhs.net
}

Keywords: hypofractionation; BC2001; BCON; bladder cancer

Received: June 18,2021 Accepted: June 21, 2021 Published: August 17, 2021

Copyright: (C) 2021 Mariam et al. This is an open access article distributed under the terms of the Creative Commons Attribution License (CC BY 3.0), which permits unrestricted use, distribution, and reproduction in any medium, provided the original author and source are credited.

\section{ABSTRACT}

One third of patients with bladder cancer present with muscle invasive bladder cancer (MIBC) which has a poor prognosis. International guidelines for the management of MIBC recommend radical cystectomy or bladder-preserving treatment based on radical radiotherapy with a form of radiosensitisation. In the UK, both conventional fractionation with $64 \mathrm{~Gy}$ in 32 fractions and hypofractionation with $\mathbf{5 5}$ Gy in 20 fractions are standard of care options with the choice varying between centres. A meta-analysis of individual patients with locally advanced bladder cancer from two UK multicentre phase 3 trials was published recently. This study evaluated the non-inferiority of a hypofractionated schedule compared to a conventional regime. This analysis confirmed the non-inferiority of the hypofractionated regimen, and noted superior locoregional control. We discuss the relevance of these findings to current practice while considering the radiobiology of hypofractionation, the role of systemic therapies and radiosensitisation, as well as the socioeconomic benefits.

\section{INTRODUCTION}

A meta-analysis of individual patients with locally advanced bladder cancer, from two multicentre phase 3 trials done in the UK, BC2001 and BCON, was published recently [1]. BC2001 assessed the addition of chemotherapy to radiotherapy and BCON assessed hypoxia-modifying agents combined with radiotherapy [2-4]. The study evaluated the non-inferiority of a hypofractionated schedule of 55 Gy in 20 fractions when compared to a conventional regime of $64 \mathrm{~Gy}$ in 32 fractions. Not only did the study confirm the noninferiority of the hypofractionated regimen, superior locoregional control was noted with the shorter schedule. The two regimes had comparable rates of overall survival and toxicity.
Why is this important and what does it mean for current practice?

Bladder cancer is estimated to account for $3 \%$ of cancer diagnoses worldwide and 3\% of cancer-related deaths within the UK $[5,6]$. One third of patients present with muscle invasive bladder cancer (MIBC) which has a poorer prognosis. International guidelines for the management of MIBC recommend radical cystectomy or bladder-preserving treatment based on radical radiotherapy with a form of radiosensitisation [7-9]. Most bladder-preserving schedules involve prior transurethral resection of bladder tumour (TURBT). There is level 3 evidence supporting the use of radiosensitisation with either chemotherapy or hypoxia modification $[2-4,10]$. Neoadjuvant chemotherapy or 
immunotherapy may also precede radical cystectomy or radiotherapy [11-13].

Previous attempts to compare outcomes of cystectomy and radical radiotherapy in a randomised controlled trial closed prematurely due to difficulties in recruitment [14]. Nevertheless, large retrospective studies have demonstrated comparable rates of overall survival in patients undergoing the two treatments when known prognostic factors are accounted for [15]. In the UK, both conventional fractionation with 64 Gy in 32 fractions and hypofractionation with 55 Gy in 20 fractions are standard of care options with the choice varying between regional centres. The superiority of the hypofractionated regime in terms of invasive locoregional recurrence and comparable toxicity profiles, as shown in this metanalysis [1], strongly suggests that this regimen should be adopted as the standard of care for bladder preservation in patients with locally advanced bladder cancer. In the BC2001 trial $77.5 \%$ of patients receiving 20 fractions had invasive locoregional control by 3 years, relative to $74.2 \%$ for those receiving 32 fractions. In the BCON trial $63.5 \%$ of patients receiving 20 fractions had invasive locoregional control at 3 years relative to $56.2 \%$ for patients receiving 32 fractions. Local control was achieved at high rates in both trials despite high proportions of patients having incomplete resections. This suggests that TURBT may not be an essential step in bladder preservation and incomplete resection should not be an exclusion criterion. Incomplete TURBT is probably best viewed as merely a surrogate for a higher stage and therefore will also predict a poorer outcome with surgery or bladder preservation.

\section{What is hypofractionation and why does it work?}

A fundamental concept of radiobiology is that a single dose of ionising radiation will be more effective at killing a cancer cell compared to the same dose divided into smaller fractions [16]. Fractionation is vital to protect normal tissues. The radiosensitivity of tissue is underpinned by an interplay between the 5 Rs of radiobiology: repair, redistribution, reoxygenation, repopulation and intrinsic radiosensitivity. The linear quadratic model of tissue radiobiological characteristics estimates that different tissues have dissimilar sensitivities to fractionation [17]. The $\alpha / \beta$ ratio quantifies fractionation sensitivity; $\alpha$ represents unrepairable lesions after radiotherapy, and is in effect a parameter of radiosensitivity, and $\beta$ represents repairable sublethal lesions. Bladder cancer, which is considered a rapidly proliferating tumour, may be assumed to have a high $\alpha / \beta$ ratio and lower fractionation sensitivity. This means that convention has assumed that bladder cancer radiotherapy is best given as 2 Gy per fraction. However, the results of the meta-analysis of $\mathrm{BCON}$ and $\mathrm{BC} 2001$ with the superiority of moderate hypofractionation contradicts this convention. There are a number of potential explanations for this, but it is likely that accelerated repopulation is more important than previously thought and that the $\alpha / \beta$ ratio of bladder cancer is lower. In this case, the overall treatment time becomes crucial in improving the outcome of treatment. Mathematical modelling has suggested that accelerated repopulation kicks in after 5 weeks for bladder cancer meaning that treatment is best completed in less than 5 weeks [18].

A key concern with hypofractionation regimes is late toxicity. Long term patient-reported outcome measures (PROMS) for BC2001 show that there is no adverse impact from hypofractionation nor from the addition of chemotherapy to radiotherapy, with around two thirds of patients showing a long-term gain in PROMS compared to baseline [19]. Additionally, the BCON trial outcomes show no differences in late toxicities between treatment groups or fractionation schedules. Although there was no detriment in late toxicity for the hypofractionation schedule in the meta-analysis, with the advent of advanced radiation techniques in image guidance as well as intensity modulated radiotherapy, we are now able to better conform high-dose radiation to the target volume. This has the potential to reduce long-term side-effects further.

\section{The role of systemic therapies}

Neoadjuvant chemotherapy has clinical benefit and is offered as standard of care in the UK prior to bladder preservation $[8,11,12]$. However, trials of neoadjuvant chemotherapy in bladder preservation predated the use of radiosensitising agents. Recent data from the BC2001 trial showed that radiosensitising chemotherapy improves locoregional control even in patients treated with neoadjuvant chemotherapy [20]. However, there is no robust evidence of benefit with the use of neoadjuvant chemotherapy in patients treated with radical radiotherapy and a radiosensitiser. The role of adjuvant chemotherapy is not as well characterised due to early closure and/or poor recruitment to trials resulting in a lack of level 1a evidence $[21,22]$. There is much interest in immunotherapeutics in this group of patients, but for now, neoadjuvant, concurrent or adjuvant immunotherapy is for trial use only.

\section{What about radiosensitisation?}

The combination of radiotherapy and a radiosensitising agent is thought to work synergistically to improve the overall clinical benefit achieved with radiotherapy alone [23]. A number of different radiosensitisers are used alone or in combination including 5-Fluorouracil (5-FU) with mitomycin-C (MMC), gemcitabine, cisplatin, carbogen and nicotinamide [7]. In BC2001, patients received either radical radiotherapy alone or with concomitant 5-FU and MMC whilst BCON compared hypoxia modification with carbogen and nicotinamide [2-4]. Of note, improvement in invasive locoregional control was seen with radiosensitisation in both trials. A hypoxic tumour microenvironment promotes tumour 
survival and progression through various mechanisms including induction of the angiogenic switch and alterations in cellular metabolism [24, 25]. Hypoxia also underpins treatment resistance to both radiotherapy and systemic agents. Hypoxia modifying agents, such as nicotinamide (vitamin B3 analogue) and carbogen (a mixture of 95-98\% oxygen and $2-5 \%$ carbon dioxide), improve oxygenation of the tumour microenvironment hence mitigating this effect [26]. Despite decades of radiobiological studies in hypoxia modification, there has been poor uptake as standard of care [27]. The BCON biobank has been of great use in evaluating the potential of predictive biomarkers for hypoxia modification. Necrosis and a 24 gene transcriptomic signature can predict patients who respond to carbogen and nicotinamide [28].

\section{Socioeconomic benefits of hypofractionation}

The rapid evolution of radiotherapy technology has been accompanied by mounting costs. Efforts to quantify and rationalise these costs by various groups, including the European Society for Radiotherapy and Oncology in the Quantification of Radiation Therapy Infrastructure and Staffing Needs study, have demonstrated the high degree of variability in radiotherapy resources including highlyskilled personnel across Europe [29, 30]. The Health Economics in Radiation Oncology project was launched to both give a complete picture of these disparities and to provide real-world solutions [31]. Although no such projects have been undertaken to assess the situation in low and middle-income countries (LMIC), The Global Cancer Observatory and International Atomic Energy Agency Directory of Radiotherapy Centres data has shed some light on the circumstances [32]. These data suggest that $50-90 \%$ of cancer patients in LMICs have limited access to treatment, with significant shortages in equipment and personnel [33]. There are huge potential gains to be made through the use of hypofractionated regimes in these settings; shorter regimes free up equipment, save patient and clinician time and have lower day-to-day costs such as transportation fees [34, 35]. Such gains, of course, also apply to high income countries.

The ongoing COVID-19 pandemic has had significant impacts on radiotherapy delivery, as detailed in a recent population-based study [36]. Though there was an overall fall in mean weekly radiotherapy courses during the first wave in the UK's National Health Service, the number of courses of bladder radiotherapy increased by $64 \%$. This may reflect increased use of radiotherapy as a preferred definitive treatment option during times of critical clinical pressures, faced particularly in cancer surgical services. Rapid guidelines issued by the National Institute of Clinical Excellence and the Royal College of Radiologists highlighted bladder cancer as priority level 1 (the highest priority level on a scale of 1-5) for the provision of radiotherapy $[37,38]$. The adoption of ultrahypofractionated regimes, based on the FAST-Forward trial in the adjuvant setting for breast cancer $[39,40]$ and PACE-B or HYPO-RT for radical prostate cancer [41, 42], increased during the pandemic. There is little evidence for ultrahypofractionation in the radical treatment of bladder cancer, however, there was an increased uptake of hypofractionated regimes [36]. As a result, treatment attendances fell considerably even after lockdown easing due to the continued use of hypofractionated regimes [36], with the intended benefit of reducing footfall. It appears that the practicalities of hypofractionation, paired with optimal clinical outcomes, in times of great clinical pressures have led to its wider acceptance in a number of solid tumours including bladder cancer.

\section{Final word}

The BC2001 and BCON meta-analysis supports the adoption of a hypofractionated schedule of 55 Gy in 20 fractions as standard of care in locally advanced bladder cancer due to superiority in locoregional control with comparable overall survival and no increase in side-effects. The 55 Gy in 20 fraction schedule can be safely delivered with radiosensitisation and there is level 1 evidence that this improves outcomes compared to radiotherapy alone. There are clear health economic benefits when adopting hypofractionated regimes with radio-sensitisation, with particular importance in future pandemic preparedness. These benefits may allow for more equitable distribution of resources, especially where there are limitations, and in times of severe clinical pressure.

\section{Author contributions}

All authors contributed to the final manuscript.

\section{ACKNOWLEDGMENTS}

Peter Hoskin and Ananya Choudhury are supported by the NIHR Manchester Biomedical Research Centre.

\section{CONFLICTS OF INTEREST}

Yee Pei Song: Bayer - Honorarium, Merck Serono - Advisory board.

\section{REFERENCES}

1. Choudhury A, Porta N, Hall E, Song YP, Owen R, MacKay R, West CML, Lewis R, Hussain SA, James ND, Huddart $\mathrm{R}$, Hoskin P, and BC2001 and BCON investigators. Hypofractionated radiotherapy in locally advanced bladder cancer: an individual patient data meta-analysis of the BC2001 and BCON trials. Lancet Oncol. 2021; 22:246-55. https://doi.org/10.1016/S1470-2045(20)30607-0. [PubMed] 
2. James ND, Hussain SA, Hall E, Jenkins P, Tremlett J, Rawlings C, Crundwell M, Sizer B, Sreenivasan T, Hendron C, Lewis R, Waters R, Huddart RA, and BC2001 Investigators. Radiotherapy with or without chemotherapy in muscleinvasive bladder cancer. N Engl J Med. 2012; 366:1477-88. https://doi.org/10.1056/NEJMoa1106106. [PubMed]

3. Huddart RA, Hall E, Hussain SA, Jenkins P, Rawlings C, Tremlett J, Crundwell M, Adab FA, Sheehan D, Syndikus I, Hendron C, Lewis R, Waters R, James ND. Randomized noninferiority trial of reduced high-dose volume versus standard volume radiation therapy for muscle-invasive bladder cancer: results of the BC2001 trial (CRUK/01/004). Int J Radiat Oncol Biol Phys. 2013; 87:261-69. https://doi. org/10.1016/j.ijrobp.2013.06.2044. [PubMed]

4. Hoskin PJ, Rojas AM, Bentzen SM, Saunders MI. Radiotherapy with concurrent carbogen and nicotinamide in bladder carcinoma. J Clin Oncol. 2010; 28:4912-18. https:// doi.org/10.1200/JCO.2010.28.4950. [PubMed]

5. Saginala K, Barsouk A, Aluru JS, Rawla P, Padala SA, Barsouk A. Epidemiology of Bladder Cancer. Med Sci (Basel). 2020; 8:15. https://doi.org/10.3390/ medsci8010015. [PubMed]

6. Cancer Research UK. https://www.cancerresearchuk.org/ health-professional/cancer-statistics/statistics-by-cancertype/bladder-cancer. Accessed May 2021.

7. Song YP, McWilliam A, Hoskin PJ, Choudhury A. Organ preservation in bladder cancer: an opportunity for truly personalized treatment. Nat Rev Urol. 2019; 16:511-22. https://doi.org/10.1038/s41585-019-0199-x. [PubMed]

8. National Institute for Health and Care Excellence. 2015. https://www.nice.org.uk/guidance/ng2.

9. Premo C, Apolo AB, Agarwal PK, Citrin DE. Trimodality therapy in bladder cancer: who, what, and when? Urol Clin North Am. 2015; 42:169-80, vii. https://doi.org/10.1016/j. ucl.2015.02.002. [PubMed]

10. Coppin CM, Gospodarowicz MK, James K, Tannock IF, Zee B, Carson J, Pater J, Sullivan LD, and The National Cancer Institute of Canada Clinical Trials Group. Improved local control of invasive bladder cancer by concurrent cisplatin and preoperative or definitive radiation. The National Cancer Institute of Canada Clinical Trials Group. J Clin Oncol. 1996; 14:2901-07. https://doi.org/10.1200/ JCO.1996.14.11.2901. [PubMed]

11. Grossman HB, Natale RB, Tangen CM, Speights VO, Vogelzang NJ, Trump DL, deVere White RW, Sarosdy MF, Wood DP Jr, Raghavan D, Crawford ED. Neoadjuvant chemotherapy plus cystectomy compared with cystectomy alone for locally advanced bladder cancer. N Engl J Med. 2003; 349:859-66. https://doi.org/10.1056/NEJMoa022148. [PubMed]

12. Vale CL, and Advanced Bladder Cancer (ABC) Metaanalysis Collaboration. Neoadjuvant Chemotherapy in Invasive Bladder Cancer: Update of a Systematic Review and Meta-Analysis of Individual Patient Data: Advanced Bladder Cancer (ABC) Meta-analysis Collaboration. Eur Urol. 2005; 48:202-05. https://doi.org/10.1016/j.eururo.2005.04.006.
13. Necchi A, Anichini A, Raggi D, Briganti A, Massa S, Lucianò $\mathrm{R}$, Colecchia $\mathrm{M}$, Giannatempo $\mathrm{P}$, Mortarini R, Bianchi M, Farè E, Monopoli F, Colombo R, et al. Pembrolizumab as Neoadjuvant Therapy Before Radical Cystectomy in Patients With Muscle-Invasive Urothelial Bladder Carcinoma (PURE-01): An Open-Label, SingleArm, Phase II Study. J Clin Oncol. 2018; 36:3353-60. https://doi.org/10.1200/JCO.18.01148. [PubMed]

14. Huddart RA, Birtle A, Maynard L, Beresford M, Blazeby J, Donovan J, Kelly JD, Kirkbank T, McLaren DB, Mead G, Moynihan C, Persad R, Scrase C, et al. Clinical and patient-reported outcomes of SPARE - a randomised feasibility study of selective bladder preservation versus radical cystectomy. BJU Int. 2017; 120:639-50. https://doi. org/10.1111/bju.13900. [PubMed]

15. Arcangeli G, Strigari L, Arcangeli S. Radical cystectomy versus organ-sparing trimodality treatment in muscleinvasive bladder cancer: A systematic review of clinical trials. Crit Rev Oncol Hematol. 2015; 95:387-96. https:// doi.org/10.1016/j.critrevonc.2015.04.006. [PubMed]

16. Chapman JD. Single-hit mechanism of tumour cell killing by radiation. Int J Radiat Biol. 2003; 79:71-81. [PubMed]

17. van Leeuwen CM, Oei AL, Crezee J, Bel A, Franken NAP, Stalpers LJA, Kok HP. The alfa and beta of tumours: a review of parameters of the linear-quadratic model, derived from clinical radiotherapy studies. Radiat Oncol. 2018; 13:96. https://doi.org/10.1186/s13014-018-1040-z. [PubMed]

18. Maciejewski B, Majewski S. Dose fractionation and tumour repopulation in radiotherapy for bladder cancer. Radiother Oncol. 1991; 21:163-70. https://doi.org/10.1016/01678140(91)90033-d. [PubMed]

19. Huddart RA, Hall E, Lewis R, Porta N, Crundwell M, Jenkins PJ, Rawlings C, Tremlett J, Campani L, Hendron C, Hussain SA, James ND, and BC2001 Investigators. Patientreported Quality of Life Outcomes in Patients Treated for Muscle-invasive Bladder Cancer with Radiotherapy \pm Chemotherapy in the BC2001 Phase III Randomised Controlled Trial. Eur Urol. 2020; 77:260-68. https://doi. org/10.1016/j.eururo.2019.11.001. [PubMed]

20. Hussain SA, Porta N, Hall E, Salawu A, Lewis R, Sreenivasan T, Wallace J, Crundwell M, Jenkins P, Tremlett J, Huddart R, James ND, and BC2001 Investigators. Outcomes in Patients with Muscle-invasive Bladder Cancer Treated with Neoadjuvant Chemotherapy Followed by (Chemo) radiotherapy in the BC2001 Trial. Eur Urol. 2021; 79:307-15. https://doi.org/10.1016/j.eururo.2020.11.036. [PubMed]

21. Cognetti F, Ruggeri EM, Felici A, Gallucci M, Muto G, Pollera CF, Massidda B, Rubagotti A, Giannarelli D, Boccardo F, Cantiani R, Aglietta M, Bertetto O, et al, and Study Group $(\dagger)$. Adjuvant chemotherapy with cisplatin and gemcitabine versus chemotherapy at relapse in patients with muscle-invasive bladder cancer submitted to radical cystectomy: an Italian, multicenter, randomized phase III trial. Ann Oncol. 2012; 23:695-700. https://doi. org/10.1093/annonc/mdr354. [PubMed] 
22. Paz-Ares LG, Solsona E, Esteban E, Saez A, GonzalezLarriba J, Anton A, Hevia M, de la Rosa F, Guillem V, Bellmunt J. Randomized phase III trial comparing adjuvant paclitaxel/gemcitabine/cisplatin (PGC) to observation in patients with resected invasive bladder cancer: Results of the Spanish Oncology Genitourinary Group (SOGUG) 99/01 study. J Clin Oncol. 2010; 28:LBA4518. https://doi. org/10.1200/jco.2010.28.18 suppl.lba4518.

23. Lawrence TS, Blackstock AW, McGinn C. The mechanism of action of radiosensitization of conventional chemotherapeutic agents. Semin Radiat Oncol. 2003; 13:1321. https://doi.org/10.1053/srao.2003.50002. [PubMed]

24. Hanahan D, Weinberg RA. Hallmarks of cancer: the next generation. Cell. 2011; 144:646-74. https://doi. org/10.1016/j.cell.2011.02.013. [PubMed]

25. Thomlinson RH, Gray LH. The histological structure of some human lung cancers and the possible implications for radiotherapy. Br J Cancer. 1955; 9:539-49. https://doi. org/10.1038/bjc.1955.55. [PubMed]

26. Thiruthaneeswaran N, Bibby BAS, Yang L, Hoskin PJ, Bristow RG, Choudhury A, West C. Lost in application: Measuring hypoxia for radiotherapy optimisation. Eur J Cancer. 2021; 148:260-76. https://doi.org/10.1016/j. ejca.2021.01.039. [PubMed]

27. Nordsmark M, Overgaard M, Overgaard J. Pretreatment oxygenation predicts radiation response in advanced squamous cell carcinoma of the head and neck. Radiother Oncol. 1996; 41:31-39. https://doi.org/10.1016/s01678140(96)91811-3. [PubMed]

28. Song YP, Mistry H, Irlam J, Valentine H, Yang L, Lane B, West C, Choudhury A, Hoskin PJ. Long-Term Outcomes of Radical Radiation Therapy with Hypoxia Modification with Biomarker Discovery for Stratification: 10-Year Update of the BCON (Bladder Carbogen Nicotinamide) Phase 3 Randomized Trial (ISRCTN45938399). Int J Radiat Oncol Biol Phys. 2021; 8:S0360-3016(21)00241-8. https://doi. org/10.1016/j.ijrobp.2021.03.001.

29. Bentzen SM, Heeren G, Cottier B, Slotman B, Glimelius B, Lievens Y, van den Bogaert W. Towards evidence-based guidelines for radiotherapy infrastructure and staffing needs in Europe: the ESTRO QUARTS project. Radiother Oncol. 2005; 75:355-65. https://doi.org/10.1016/j. radonc.2004.12.007. [PubMed]

30. Rosenblatt E, Izewska J, Anacak Y, Pynda Y, Scalliet P, Boniol M, Autier P. Radiotherapy capacity in European countries: an analysis of the Directory of Radiotherapy Centres (DIRAC) database. Lancet Oncol. 2013; 14:e7986. https://doi.org/10.1016/S1470-2045(12)70556-9.

31. Lievens Y, Grau C. Health economics in radiation oncology: introducing the ESTRO HERO project. Radiother Oncol. 2012; 103:109-12. https://doi.org/10.1016/j. radonc.2011.12.026. [PubMed]

32. Ferlay J, Soerjomataram I, Dikshit R, Eser S, Mathers C, Rebelo M, Parkin DM, Forman D, Bray F. Cancer incidence and mortality worldwide: sources, methods and major patterns in GLOBOCAN 2012. Int J Cancer. 2015; 136:E359-86. https://doi.org/10.1002/ijc.29210. [PubMed]

33. Zubizarreta EH, Fidarova E, Healy B, Rosenblatt E. Need for radiotherapy in low and middle income countries - the silent crisis continues. Clin Oncol (R Coll Radiol). 2015; 27:10714. https://doi.org/10.1016/j.clon.2014.10.006. [PubMed]

34. Hennequin C, Guillerm S, Quero L. Rationale for hypofractionation. Cancer Radiother. 2019; 23:500-02. https://doi.org/10.1016/j.canrad.2019.07.156. [PubMed]

35. Tree AC, Huddart R, Choudhury A. Magnetic Resonanceguided Radiotherapy - Can We Justify More Expensive Technology? Clin Oncol (R Coll Radiol). 2018; 30:677-79. https://doi.org/10.1016/j.clon.2018.08.013. [PubMed]

36. Spencer K, Jones CM, Girdler R, Roe C, Sharpe M, Lawton S, Miller L, Lewis P, Evans M, Sebag-Montefiore D, Roques T, Smittenaar R, Morris E. The impact of the COVID-19 pandemic on radiotherapy services in England, UK: a population-based study. Lancet Oncol. 2021; 22:309-20. https://doi.org/10.1016/S1470-2045(20)30743-9. [PubMed]

37. National Institute for Health and Care Excellence. 2020. https:// www.nice.org.uk/guidance/ng162. Accessed May 2021.

38. Birtle AJ. Guidance for management of urothelial cancer during COVID-19 pandemic. 2020. https://www.rcr.ac.uk/ sites/default/files/urothelial-cancer-covid19.pdf.

39. Murray Brunt A, Haviland JS, Wheatley DA, Sydenham MA, Alhasso A, Bloomfield DJ, Chan C, Churn M, Cleator S, Coles CE, Goodman A, Harnett A, Hopwood P, et al, and FAST-Forward Trial Management Group. Hypofractionated breast radiotherapy for 1 week versus 3 weeks (FASTForward): 5-year efficacy and late normal tissue effects results from a multicentre, non-inferiority, randomised, phase 3 trial. Lancet. 2020; 395:1613-26. https://doi. org/10.1016/S0140-6736(20)30932-6. [PubMed]

40. Coles CE, Aristei C, Bliss J, Boersma L, Brunt AM, Chatterjee S, Hanna G, Jagsi R, Kaidar Person O, Kirby A, Mjaaland I, Meattini I, Luis AM, et al. International Guidelines on Radiation Therapy for Breast Cancer During the COVID-19 Pandemic. Clin Oncol (R Coll Radiol). 2020; 32:279-81. https://doi.org/10.1016/j.clon.2020.03.006. [PubMed]

41. Brand DH, Tree AC, Ostler P, van der Voet H, Loblaw A, Chu W, Ford D, Tolan S, Jain S, Martin A, Staffurth J, Camilleri P, Kancherla K, et al, and PACE Trial Investigators. Intensity-modulated fractionated radiotherapy versus stereotactic body radiotherapy for prostate cancer (PACE-B): acute toxicity findings from an international, randomised, open-label, phase 3, non-inferiority trial. Lancet Oncol. 2019; 20:1531-43. https://doi.org/10.1016/ S1470-2045(19)30569-8. [PubMed]

42. Widmark A, Gunnlaugsson A, Beckman L, ThellenbergKarlsson C, Hoyer M, Lagerlund M, Kindblom J, Ginman C, Johansson B, Björnlinger K, Seke M, Agrup M, Fransson $\mathrm{P}$, et al. Ultra-hypofractionated versus conventionally fractionated radiotherapy for prostate cancer: 5-year outcomes of the HYPO-RT-PC randomised, non-inferiority, phase 3 trial. Lancet. 2019; 394:385-95. https://doi. org/10.1016/S0140-6736(19)31131-6. [ [PubMed] 